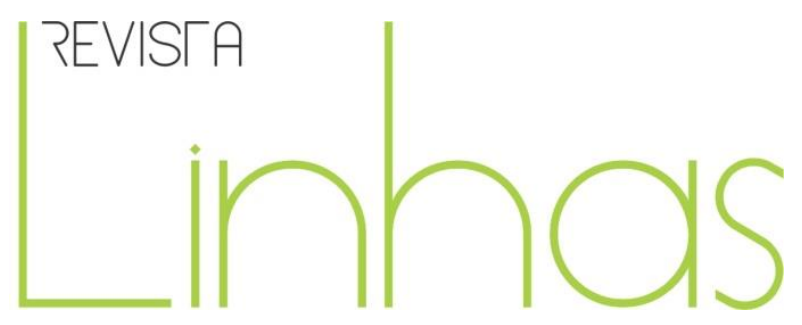

\title{
As culturas infantis interrogam a formação docente: tessituras para a construção de pedagogias descolonizadoras
}

\begin{abstract}
Resumo
O presente artigo tem como objetivo problematizar de que modo o reconhecimento das culturas infantis possibilita repensar os modelos canônicos de exercer a docência na educação infantil, tomando como ponto de partida o desvelamento das vivências de crianças negras e não negras, nas creches e pré-escolas, e em uma casa de candomblé. Trata-se de um estudo qualitativo com interlocução crítica entre os estudos pós-colonialistas, as relações étnico-raciais e a pedagogia da infância. Para tanto, partimos das tensões entre o marxismo e o pensamento pós-colonialista, procurando apresentar aportes e possibilidades de construções de pedagogias descolonizadoras que tenham como gênese a intempestividade das infâncias. Os resultados apontam para a necessidade de construção de pedagogias que propiciem a escuta das diferentes infâncias na educação infantil e que possibilitem ouvir o que as crianças pequenininhas e pequenas querem dizer, com suas diferentes linguagens, assim como a possibilidade de estabelecer relações entre os princípios da cosmologia de mundo yorubá, oralidade, ancestralidade e corporalidade com o parecer $\mathrm{CNE} / \mathrm{CP} / 03 / 2004$, que estabelece as Diretrizes Curriculares Nacionais para a Educação das Relações Étnico-Raciais e para o Ensino de História e Cultura Afro-Brasileira e Africana, bem como com o parecer $\mathrm{CNE} / \mathrm{CB} / 20 / 2009$, que estabelece Diretrizes Curriculares Nacionais para a Educação Infantil. Neste contexto, lançamos um convite à construção de pedagogias descolonizadoras que colaborem para a equidade na educação infantil e inspirem novas políticas públicas de superação do racismo e de distorções que transformam diferenças em desigualdades.
\end{abstract}

Palavras-chave: Educação Infantil. Culturas Infantis. Relações Raciais. Criança Pequena. Infâncias.
Ellen Gonzaga Lima Souza

Universidade Federal de Lavras UFLA - Minas Gerais/MG - Brasil ellenl.souza@ded.ufla.br

\section{Flávio Santiago}

Universidade Estadual de Campinas - UNICAMP Campinas/SP - Brasil

flavio.fravinho@gmail.com

\section{Ana Lúcia Goulart de Faria Universidade Estadual de Campinas - UNICAMP - Campinas/SP - Brasil cripeq@unicamp.br}

\section{Para citar este artigo:}

SOUZA, Ellen Gonzaga Lima; SANTIAGO, Flávio; DE FARIA, Ana Lúcia Goulart. As culturas infantis interrogam a formação docente: tessituras para a construção de pedagogias descolonizadoras. Revista Linhas. Florianópolis, v. 19, n. 39, p. 80-102, jan./abr. 2018. 


\title{
Childhood peer cultures interrogate teacher training: tessituras for the construction of decolonizing pedagogies
}

\begin{abstract}
The present article aims to problematize the manner in which the recognition of childhood peer cultures allows one to rethink the canonical models of exercising teaching activities in early childhood education; as its starting point, it takes the unveiling of experiences of both black and non-black children in daycare centers, pre-school classes, and in a Candomble house. This is a qualitative study with critical interlocution among the post-colonial studies, ethno-racial relations, and childhood pedagogy. We draw on tensions between Marxism and Postcolonialist thought and attempt to present contributions and possibilities with a view to building decolonizing pedagogies that are primarily based on childhood restlessness. The outcomes point to the necessity of building pedagogies that grant listening to different childhoods in early childhood education, and that enable one to hear what the tiny young children and young children want to say, in their different languages, together with the possibility of establishing relations between the principles of Yoruba world cosmology, orality, ancestry and corporeality with the statement $\mathrm{CNE} / \mathrm{CP} / 03 / 2004$, that sets the National Curriculum Guidelines for the Education of EthnoRacial Relationships and for the Teaching of AfroBrazilian and African History and Culture, as well as with the statement $\mathrm{CNE} / \mathrm{CB} / 20 / 2009$, which establishes the Nacional Curriculum Guidelines for Childhood Education. In this context, we launch an invitation for the construction of decolonizing pedagogies that may contribute to equity in early childhood education and may inspire new public policies to overcome racism and distortions that transform differences in inequalities.
\end{abstract}

Keywords: Early Childhood Education. Peer Cultures. Racial Relations. Tiny Young Children. Childhoods. 
Este artigo tem como objetivo problematizar de que modo o reconhecimento das culturas infantis possibilita repensar os modelos canônicos de exercer a docência na educação infantil, tomando como eixo central o desvelamento das vivências de crianças negras e não negras nas creches da região metropolitana de Campinas e, em uma casa de candomblé da zona norte de São Paulo.

Para alcançar tal objetivo, partimos de uma problematização acerca dos processos de hierarquização e invisibilização da produção das culturas infantis nas sociedades capitalistas, tendo como referência teórica as tensões entre o marxismo e o pensamento pós-colonialista, procurando apresentar aportes e possibilidades de construções de pedagogias descolonizadoras que tenham como gênese a intempestividade das infâncias.

A disposição de escuta da infância e das crianças exige que nos arrisquemos a ouvir os gestos, as paredes, as brincadeiras, os movimentos, abrindo os ouvidos até mesmo para aquilo que não emite nenhum som (SANTIAGO, 2016). É permitir trazer as raízes crianceiras, as visões comungantes e oblíquas das coisas, é dizer sem pudor que o escuro ilumina, usar a palavra para compor silêncios (BARROS, 2010). Para a construção dessa forma de ouvir é fundamental, como destaca Manferrari (2011), escutarmos o mundo pela imaginação, "assumindo o compromisso na troca narrativa, cada um pode reconhecer que o outro é o outro realmente, com a diferença, a imprevisibilidade e a importância que lhe compete enquanto ser único" (MANFERRARI, p. 59).

O eixo descolonizador dessa construção metodológica está em abrir a possibilidade de experienciar uma polifonia:

a partir das tensões entre o marxismo e o pensamento pós-colonialista, procuramos marcar uma ruptura com a tradição epistemológica submetida a princípios cartesianos e colonialistas, ressignificando antropofagicamente os saberes, criando novos arcabouços teóricos que visem à produção de outro modelo de ciência, conhecimento e educação. (SANTOS; SANTIAGO; FARIA, 2016, p. 193)

A partir dessa escolha metodológica, faz-se necessário ressaltar que a tarefa do/a pesquisador/a, como aponta Spivak (2010), deve ser a de criar espaços por meio dos quais 
os sujeitos possam falar e ser ouvidos em suas diferentes linguagens, desarticulando as amarras coloniais de subalternização dos saberes e dos atores da pesquisa.

Para a construção desse processo, é imprescindível "estranhar o familiar e familiarizar-se com o exótico" (VELHO, 1978, p. 28), de modo a mostrar diferentes encontros que serão vivenciados com as crianças. Lembrando sempre que as experiências que nos "cortam" transbordam a fixidez das categorias "forjadas cientificamente". Parte integrante desse processo é tomada pela simplificação das experiências e pela distorção perceptiva, limitando a compreensão das relações sociais em categorias estruturais de inteligibilidade cultural.

Se quisermos continuar a utilizar termos provenientes de perspectivas empiristas diversas, uma analogia mimético-analógica é simultaneamente perceptual, sensorial, afetiva etc. Na verdade, isso é desnecessário, porque uma analogia é estabelecida pelo corpo todo, situado temporalmente e espacialmente. Ela não pode ser nem vista nem como objetiva e nem como subjetiva, porque o corpo analógico-remissivo é aquele que conecta rastros de memória de dois ou mais jogos de linguagens que encenam práticas culturais que participam de arquivos culturais, na maior parte das vezes intangíveis. (MIGUEL, 2015, p. 42-43)

Os meninos e as meninas nos mostram como a fixidez de categorias, bem como as suas não intersecções, limitam a compreensão das produções de culturas infantis. As crianças pequenininhas ${ }^{1}$ e pequenas, negras e não negras estão reinterpretando o mundo, as relações sociais, de poder, de idade, de classe, de gênero e raciais de "corpo inteiro". O corpo aqui descrito é metafórico, compreendido como fluxo cultural produzido nas relações entre pares, constituindo-se como o ato de produção dos significados e signos².

\footnotetext{
${ }^{1}$ Essa designação foi inicialmente utilizada por Patrícia Dias Prado (1998), que traduziu a palavra italiana picolissimi, ou os "muito pequenos", e refere-se às crianças na idade de 0 a 3 anos completos. 0 objetivo principal dessa denominação, segundo Prado (1998), resulta da necessidade emergente de se produzir novos conhecimentos relativos dentro das Ciências Sociais a respeito da criança pequena brasileira, tanto mais, sobre as muito pequenas, que não conhecemos, senão pela Medicina e pela Psicologia.

2 Ao encontro desse pensamento, Willian Corsaro (2003, 2011) propõe o conceito de "reprodução interpretativa", que possui três características fundantes: a apropriação criativa das informações e o conhecimento proveniente do mundo adulto; a produção e a participação das crianças entre si; e as contribuições de reprodução da cultura adulta. O termo reprodução enfatiza o quanto as crianças são constrangidas, pela estrutura social das diversas instituições culturais, sociais e políticas, frequentemente
} 
O que procuramos evidenciar com esta metáfora é justamente o que Florestan Fernandes, na década de 1940, com seus estudos pioneiros no Brasil a respeito das brincadeiras e dos grupos infantis, no bairro do Bom Retiro, em São Paulo, descreveu como sendo os "traços diversos da cultura anemológica que, abandonados total ou parcialmente, transferem-se para o círculo infantil, por um processo de aceitação, incorporando-se à cultura do novo grupo" (FERNANDES, 2004, p. 215).

Em sua pesquisa, Fernandes (2004) concebe a cultura infantil como o conjunto de relações em que as crianças têm oportunidade de manter contatos pessoais e de interagirem socialmente com outras crianças desenvolvendo rotinas, artefatos, valores e interesses que possibilitam a incorporação de normas e padrões de comportamento em suas personalidades. Por meio da experiência direta e concreta, elas aprendem "como agir em cada circunstância, na qualidade de parceiro e membro de dado agrupamento social há um tempo" (FERNANDES, 2004, p. 207). Ao encontro desse pensamento, Corsaro (2011, p. 15) destaca que "as crianças são agentes sociais, ativos e criativos, que produzem suas próprias e exclusivas culturas infantis, enquanto, simultaneamente, contribuem para a produção das sociedades adultas".

A produção de cultura está na essência da nossa humanidade; como destaca Brandão (2010), é o fato de produzirmos cultura que nos torna humanos, pois as diferentes culturas são resultados de nossos esforços humanos de criação, adaptação e recriação.

E somos humanos porque, sendo seres da natureza, nós nos construímos como sujeitos sociais criadores de cultura. Tudo o que existe entre a pessoa, a pedagogia e a educação constitui planos, conexões, fios e tramas do tecido complexo e sempre mutante de uma cultura. Somos humanos porque criamos cultura e continuamente as transformamos. $\mathrm{E}$ uma cultura ou algumas existem entre nós e em nós objetiva e subjetivamente. (BRANDÃO, 2010, p. 100)

No entanto, é necessário afiançar que não podemos perder a percepção sóciohistórica desse processo, pois, como salientam Marx e Engels (2000, p. 187).

ao longo da vida, a se tornarem semelhantes. Entretanto, com a palavra interpretativa, o autor salienta que as crianças ao internalizarem a cultura com que têm contato contribuem ativamente para a mudança social e cultural, já que a reelaboram e a reinterpretam. 
O modo pelo qual os homens [mulheres, crianças] produzem os seus meios de vida dependem inicialmente da constituição mesma dos meios e vida encontrados aí e a ser produzidos. Este modo da produção não deve ser considerado só segundo o aspecto de ser a reprodução da existência física dos indivíduos. Ele já é antes uma maneira determinada de atividade desses indivíduos, uma maneira determinada de manifestação na sua vida, um modelo de vida determinado.

O tempo tornou-se um elemento regulador desse processo, "pela divisão de trabalho, supervisão do trabalho, multas, sinos e relógios, incentivos em dinheiro, pregações e ensino, supressão das feiras e dos esportes - formaram-se novos hábitos de trabalho, impôs-se uma nova disciplina de tempo" (THOMPSON, 1998, p. 297).

A lógica produtivista do capitalismo leva a uma produção social da inexistência, a hierarquia de saberes e a homogeneização da experiência social. [...] É uma compreensão parcial e seletiva do mundo que cria dicotomias e hierarquias; e a razão proléptica, que "concebe o futuro a partir da monocultura do tempo linear". (SANTOS, 2014, p. 66)

Neste sentido, descolonizar começa por se recolocar no tempo e no espaço, pois tais instâncias também são construções sociais forjadas por uma perspectiva colonizada; não é inócuo que uma das frases mais simbólicas da sociedade capitalista seja a proferida por Benjamin Franklin, time is Money, em 1748, no ensaio intitulado Conselhos para um jovem comerciante. Esta frase retrata o roubo do tempo pela necessidade de acumulação do capital, não o tempo indispensável à sobrevivência imediata, utilizado para dormir e comer, "mas do tempo das necessidades físicas, intelectuais e morais do convívio com o outro, tempo da festa, do jogo, da educação, da curiosidade, etc." (PIOZZI, 2015, p.138).

A infância, enquanto momento de experimentação do mundo, da liberdade criativa torna-se perda de tempo e consequentemente de dinheiro; criemos então condições de minimizar os gastos e aumentar o lucro, e a opção no caso das crianças advém da colonização adultocêntrica ${ }^{3}$.

\footnotetext{
${ }^{3}$ No ano de 2016, enquanto escrevíamos este texto, tivemos um "golpe" no Brasil a favor dos interesses do capital; em relação à educação, constatamos um avanço significativo da valorização dos interesses dos grandes empresários reformadores, bem como de um processo de privatização. Ainda nos ronda o retrocesso de décadas nas conquistas políticas da educação infantil, existe a possibilidade das creches
} 
Assim, as orientações nos momentos de formação de professores e professoras induzem a tratar o tempo colonizado de padrões eurocêntricos como o centro das relações na Educação Infantil. É muito comum nos depararmos em seminários e planejamentos com a palavra rotina, que sempre é acompanhada pela hora padrão de: dormir, comer, ir ao banheiro, tomar banho, brincar, falar, andar, começar, terminar, chegar, sair, etc. Essa etapa da Educação Básica também é “vítima” do padrão social que tenta determinar que a infância de cada sujeito tenha dia e hora para terminar; quanto antes isso se der, maior será o lucro social, pois é forjada mais uma peça para a engrenagem adultocêntrica. "O destino das crianças é a espera - paciente, até tornaremse adultas, para ter sua construtividade reconhecida, o que dizer sobre assuntos sociais, para ser parte da coletividade de cidadãos" (QVORTRUP, 2014, p. 32).

Neste momento político de expansão do modelo de escolarização, é necessário destacar que para algumas correntes teóricas as crianças só passam a construir cultura, ou seja, a tornarem-se sujeitos, a partir da aquisição das estruturas mentais para a elaboração de relações abstratas e da aquisição da linguagem oral. Mauss (2010), no texto Três observações sobre a Sociologia da Infância, já apontava como essa forma de percepção constrói um conceito de criança colonizada, o qual individualiza a experiência da infância, provocando Jean Piaget a fazer uma psicologia da criança em geral e não uma psicologia da "criança mais civilizada".

A criança marroquina [precisa Mauss] é habilidosa e trabalha bem mais cedo do que nossas crianças. Sobre certos pontos, portanto, ela raciocina antes e mais rápido e de outro modo - manualmente do que as crianças de nossas boas famílias burguesas. (MAUSS, 2010, p. 239)

A historiadora Scott (1998), ao afirmar que experiência é a história de um sujeito, contribuiu para refletirmos a respeito das afirmações de Mauss (2010), permitindo questionar os conceitos generalizados de etapas de desenvolvimentos, ou de

serem devolvidas para a assistência social e uma antecipação da escola para as crianças de quatro a cinco anos, implementando sistemas de ensino apostilados e adotando metas de alfabetização e modelos escolares de colonização alfabética. 
experiências de infâncias estabelecidas a partir de um único recorte, seja este eurocêntrico ou não.

A experiência, como destaca Brah (2006) ao encontro do pensamento de Scott (1998), é um processo de significação, que é a condição para a constituição daquilo a que chamamos realidade, cultura, história. É a necessidade de destacar a noção de experiência não como diretriz imediata para a "verdade", mas "como uma prática de atribuir sentido, [...] como uma luta sobre condições materiais e significado" (BRAH, 2006, p. 333).

O adultocentrismo (in)visibiliza as experiências das crianças pequenininhas e pequenas, marcando-as com interpretações recortadas de sujeito, produção cultural, linguagem e infância. Outra marca desse processo, destacada por Macedo (2016), é a subordinação que vem atrelada aos rituais da instituição escolar à disciplina e ao controle. Guattari (1987, p. 53) alerta que estas estão sendo antecipadas e que a creche já seria a iniciação aos ditames da ordem capitalista, com o objetivo de "extirpar da criança, o mais cedo possível, sua capacidade específica de expressão e em adaptá-la, aos valores, significações e comportamentos dominantes".

Por meio de inúmeras ações pedagógicas desenvolvidas no espaço da educação infantil, são criados processos de iniciação ao capital e ligação dos sujeitos às estruturas sociais ideologicamente construídas pelo capitalismo. O processo de iniciação não se limita somente ao fazer docente, mas também é construído por intermédio dos diferentes elementos que compõem o espaço da creche e pré-escola, as figuras, os objetos; os desenhos pendurados nas paredes incitam a imaginação infantil a criar modelos sociais de vida e mecanismos de experienciação do mundo, transbordando-se nas tessituras do tempo. "As crianças estão sendo anuladas nas suas múltiplas possibilidades de ser criança" (SANTOS, 2014, p. 66).

A "arte de ensinar" torna-se assim um elemento colonizador por excelência, que não legitima outras possibilidades de criações, e não abre espaço para as peraltagens poéticas das crianças. Esse processo, como aponta Miranda (2009, p. 29), é derivado dos pressupostos de Comenius, que instigava os/as docentes a imaginarem antes dos estudantes das primeiras letras as coisas do mundo e suas palavras, "silenciando a imaginação ao apresentar de antemão as imagens do mundo". 
Foi essa crença colonizada que transfigurou a criança em infante, bem como em infância, não só no período temporal de imaturidade biológica para procriar e assegurar a continuidade da espécie, mas também o período cultural a ela correspondente, agora transfigurada em período temporal de incapacidade generalizada e/ou de preparo para a aquisição de capacidades por vir [...] (MIGUEL, 2015, p. 39)

Como descolonizar esse processo? Dentre as inúmeras possibilidades, podemos tomar como ponto de partida outras cosmologias, estabelecendo interlocuções com a lógica colonizadora que nos fora imposta, ou seja, não propomos aqui um rompimento absoluto, simplesmente porque não seria possível, mas para a construção de pedagogias descolonizadoras, inspiradas na nkisi ${ }^{4}$ Kitembo, que pode ser traduzido como tempo. Conta uma lenda de Angola, que Kitembo era um homem muito agitado, que fazia e resolvia muitas coisas ao mesmo tempo. Entretanto, esse homem vivia reclamando e cobrando de Nzambi que o dia era muito pequeno para fazer e resolver tudo que quisesse. Um dia, Nzambi Ihe disse: “Eu errei em sua criação, pois você é muito apressado". Ele então respondeu a Nzambi: "Não tenho culpa se o dia é pequeno e as horas miúdas, não dando tempo para realizar tudo que planejo". A partir desse momento, Nzambi então determinou que esse homem passasse a controlar o tempo, tendo o domínio dos elementos da natureza. Assim nasceu o Nkisi Kitembo5.

Tomando como compreensão de tempo a orientação africana acima destacada, convidamos à construção de pedagogias descolonizadoras que invertam a relação de poder entre tempo e humanidade que experienciamos na atualidade, pois o modelo capitalista, pautado no antagonismo de classe e nas mazelas do racismo e sexismo, que influencia significativamente a educação brasileira, nos traz uma experiência absolutamente desconfortável em relação ao tempo, como se estivéssemos sempre atrasados, como se fosse imprescindível adiantar as crianças, mas adiantar para ser mais um adulto produtivo controlado pelo tempo, que na sociedade atual é sinônimo de capital.

\footnotetext{
${ }^{4}$ Nkisi são forças espirituais que podem ser representadas, ou não, por objetos cultuados no Brasil pelo candomblé de nação Bantu, conhecido como Angola.

${ }^{5}$ Lenda transmitida nos terreiros pela tradição oral.
} 
Mas, Kitembo trazido acima é obediente ao homem, e não o inverso, foi determinado pela autoridade criadora do universo que o tempo fosse de controle da humanidade. Repensar o tempo implica reorientar-se no espaço do próprio corpo, conforme aconselha o sábio africano Bandiagara Tierno Bokar: "se queres saber quem sou, se queres que te ensine o que sei, deixa um pouco de ser o que tu és e esquece o que sabes" (BOKAR apud KI-ZERBO, 2010, p. 212). Tal conselho pode ser reaproveitado para pensarmos com as crianças; é imprescindível buscar a criança que fomos e colocá-la na relação todos os tempos, passado e futuro convivendo no presente.

Assim, não podemos assumir a infância como algo que pertence às crianças deste tempo:

No mundo moderno, a inocência infantil (vista como um momento de preservação) e a violência contra a criança (como reflexo de uma extrema imposição) convivem no mesmo espaço. O "direito" de compartilhar do mundo adulto representa de fato a própria ausência de direitos da criança, sobretudo da criança pobre. Com as crianças que têm sua infância furtada por condições de existência adversas ao mundo infantil do exercício do sonho e da liberdade, a sociedade compartilha as mazelas do capitalismo voraz: a miséria, a criminalidade e, na melhor das hipóteses, a conformadora inserção no mundo do trabalho. (ROCHA, 1997, p. 28)

A estrutura de mundo capitalista colocou a infância em uma condição paradoxal; se de um lado há um imaginário forjado de inocência e proteção, de outro, convivemos com a desigualdade extrema que leva a condições sociais desumanas, ou ainda, que torna algumas crianças mais humanas do que outras (sic.).

Isso quer dizer que, diferente do que se pressupõe normalmente, não é a presença de adultos que constitui, necessariamente, a condição suficiente para transformar tempo não protegido em tempo protegido. Às vezes, e de modo mais razoável, seria necessária a redução ou a eliminação das condições que se apresentam como riscos ou ameaças para satisfazer a demanda das crianças por espaços tomados como livres e sem restrições. (QVORTRUP, 2015, p. 24)

A pesquisa de mestrado de Souza (2012) demonstrou que professoras de Educação Infantil formam uma percepção colonizada referente às crianças negras, como 
se estas não tivessem infância, ou seja, a condição de ser negra elimina "naturalmente" a condição de ser criança. As expectativas das professoras ao se depararem com uma criança negra em sala de aula perpassavam por duas possibilidades: a crença de que aquela criança devia ser protegida, pois estava necessariamente sujeita ao racismo, e a compreensão de que aquela criança negra devesse agir de forma combativa e mostrasse orgulho de seu pertencimento étnico-racial.

Dizendo de outra forma, a colonização atravessou os sentidos das referidas professoras, que mesmo buscando por formações que possibilitassem a construção de uma educação que não coadunasse com o racismo, suas percepções lhes permitiram captar apenas algumas técnicas operacionais, como: inserir imagens de negros/as nas atividades, questionar os estereótipos raciais presentes nos materiais didáticos e questionar falas e posturas racistas proferidas nas creches e pré-escolas. Porém, as professoras percebem as crianças negras por meio da ausência, dúvida e negação, e são representadas por fragmentos e distorções, ou seja, com suas representações colonizadas. "A produção social destas ausências resulta na subtração do mundo e na contração do presente e, portanto, no desperdício da experiência" (SANTOS, 2002, p. 249).

Aos meninos negros e às meninas negras são interditados os direitos ao cuidado, ao afeto, à paparicação, ao acesso de bens econômicos, simbólicos e culturais. Poder-seia aqui empregar, analogicamente, a expressão conceitual "fazer viver e deixar morrer”, cunhada por Foucault (2010). Nesse contexto, outorga-se a alguns o direito de "experienciar" o mundo como criança; e, aos outros, reserva-se a morte resultante dos efeitos nefastos do racismo: uma morte social, dilacerada para além do próprio sentimento de luto.

Convém lembrar, como destaca Brah (2006), que os processos de racialização são historicamente específicos, e diferentes grupos foram racializados de maneira diversa em circunstâncias variadas, tendo, na base, distintos significantes de "diferença”.

Cada racismo tem uma história particular. Surgiu no contexto de um conjunto específico de circunstâncias econômicas, políticas e culturais, foi produzido e reproduzido através de mecanismos específicos e assumiu diferentes formas em diferentes situações. O racismo antinegro, 
o racismo anti-irlandês, o racismo antissemita, o racismo antiárabe, diferentes variedades de orientalismos: todos têm suas características distintivas [...] as histórias específicas desses vários racismos os colocam em relações particulares entre si. (BRAH, 2006, p. 344)

No caso brasileiro, podemos compreender esse fenômeno a partir dos requisitos estruturais da sociedade de classes. As manifestações racistas, os estereótipos ou as ideologias raciais são fenômenos que exprimem situações alicerçadas em um passado escravocrata, que não buscou a integração de negros e negras à sociedade e criou estratégias para justificar as desigualdades entre negros e não negros.

A partir de uma abordagem histórico-sociológica, o referido autor analisa os dilemas da inserção dos negros na ordem capitalista e competitiva, propondo que a situação de anomia social dos negros devia-se ao arcaísmo de estruturas sociais herdadas do processo de escravização. Fernandes (1965) demonstra que a mudança do estatuto de escravo para homem livre, no pós-abolição, não foi acompanhada por uma efetiva integração do negro na sociedade de classes em formação. Identifica-se a continuidade e a persistência de relações sociais fundadas no período escravista.

A integração dos negros nessas novas conjunturas sociais, embora sempre marcada no cotidiano por conflitos intensos, foi mascarada por um discurso falso de que a oportunidade era para todos; esse engodo atingiu a negros e não negros, criando o mito da democracia racial. A harmonia desse engodo terminava quando o negro, não aceitando o papel da subalternidade, criou movimentos de resistência ao racismo do cotidiano. Dentre esses movimentos de resistência, destacam-se duas importantes organizações do Movimento Negro paulistano: a Frente Negra Brasileira, e a militância de autores de O Clarim da Alvorada $a^{6}$. Nos depoimentos de José Correia Leite é possível conhecer as complexidades das organizações negras na década de 1930.

As crianças negras desde pequenininhas também criam movimentos de resistência micropolíticas, demonstrando não aceitação dos lugares sociais que o racismo lhes

\footnotetext{
${ }^{6}$ Os documentos consultados não indicam claramente o motivo imediato do surgimento da Frente Negra Brasileira. As primeiras notícias a seu respeito estão presentes nos jornais O Clarim d'Alvorada e Progresso, e tratam de reuniões e atos relativos à entidade, que, naquele momento já estava formada. O jornal $A$ Voz da Raça, porta-voz da Frente Negra, refere-se, vagamente, à fundação da entidade como uma tentativa do negro se unir, possuir organismo que lutasse pelos seus direitos e, finalmente, contar com um local onde pudesse exercer sua sociabilidade (PINTO, 2013, p. 88).
} 
confere, produzindo de modo infantil, não adultocêntrico, movimentos de resistências aos processos racistas e suas subalternizações. Por meio de diferentes movimentos de choque com o poder, os meninos negros e as meninas negras inauguram novos sentidos e "rabiscam" suas configurações corpóreas, lançando-se para o inesperado, resistindo, de modo a criar uma nova possibilidade de existência, fora de si, além do racismo. Os choros, as rebeldias são algumas das formas de uma guerrilha a favor da vida; transmutações concretas de resistência pela não pasteurização dos sujeitos (SANTIAGO, 2015).

Para além da colonização, pautada nas leis do capital, as crianças estão resistindo, transgredindo e se fazendo presentes na vida social, participando, produzindo culturas, “transformando [...] ausências em presenças" (SANTOS, 2002, p. 246).

No entanto, para percebermos esses movimentos, é necessário que estejamos dispostos a reconhecer as produções das crianças, a produção das culturas infantis como um elemento singular da infância, estando no centro reflexivo das ações pedagógicas, desenvolvidas em creches e pré-escolas, o protagonismo dos meninos e meninas pequenos e pequenininhos.

A produção das culturas infantis e as contradições existentes nas diversas relações que se estabelecem na creche, são ressaltadas por Bufalo (1997) que apresenta as diferenças e conflitos existentes nesse espaço de forma muito positiva como um elemento potencializador da pedagogia, indo ao encontro do que diz Benjamin (2002, p.114) "as tensões do trabalho coletivo são os verdadeiros educadores". (MACEDO, 2016, p. 38)

A busca pelo desvelamento do trabalho na esfera coletiva, e do reconhecimento do protagonismo infantil na construção da história exigem que estejamos dispostos [...] "não no sentido de arrumado, ordenado, determinado, mas de se pôr à disposição para alcançar, perceber a partir de seu interior, o fenômeno" (SILVA, 1987, p. 92).

Ao encontro desse processo, precisamos criar possibilidades de repensar as pedagogias, conforme destaca Rocha (1997, p. 22):

[... ] o dilema fundamental da pedagogia, associado, em essência, ao fato de ter a infância como objeto e a sociedade como meta. A intervenção 
pedagógica tem oscilado permanentemente entre o "desabrochar" de uma formação humana conduzida pela natureza e a disciplinação e a conformação a regras e modos sociais dominantes, das quais resultam diferentes formas de transgressão. No âmago deste antagonismo, consolidam-se na pedagogia alternativas fundamentadas em projetos sociais utópicos que propõem relações educativas onde autonomia e coletividade ganham novas dimensões. (ROCHA, 1997, p. 22)

Somente conseguimos articular o processo descrito por Rocha (1997) quando pensamos a descolonização das pedagogias, buscando compreender os efeitos da colonização acerca de nossas compreensões e percepções das noções de tempo, espaço, infâncias. É fundamental termos a percepção de que a colonização corresponde necessariamente à negação:

A negação de uma parte da humanidade é sacrificial, na medida em que constitui a condição para outra parte da humanidade se afirmar enquanto universal. $O$ meu argumento é que essa realidade é tão verdadeira hoje como era no período colonial. O pensamento moderno ocidental continua a operar mediante linhas abissais que dividem 0 mundo humano do sub-humano, de tal forma que os princípios da humanidade não são postos em causa por práticas desumanas. As colônias representam um modelo de exclusão radical que permanece atualmente no pensamento e práticas modernas ocidentais tal como aconteceu no ciclo colonial. (SANTOS, 2010, p. 39)

A construção da educação infantil no Brasil vem superando os ranços históricos da institucionalização da infância brasileira, que foi ligada ao assistencialismo. Atualmente, a educação infantil no Brasil corresponde à afirmação de direitos e pode ser uma importante ferramenta para a superação das desigualdades, sejam elas de ordem etária, econômica, racial, de gênero, etc. Assim, a educação infantil se estrutura em duas fortes ideias:

[...] a busca na educação infantil (e não apenas por meio da ou pela educação) de igualdade de oportunidades para as crianças; isto é, esperase, deseja-se, luta-se para que a El não produza ou reforce desigualdades (econômicas, raciais, de gênero); a adoção de uma concepção ampla de educação, aberta, indo além dos modelos que aqui conhecemos, de educação escolar; isto é uma concepção de educação em acordo com a nova maneira de olhar a criança pequena que se está construindo no 
Brasil, como ser ativo, competente, agente, produtor de cultura, pleno de possibilidades atuais, e não apenas futuras. (ROSEMBERG, 2002, p. 77)

Neste sentido, entendemos que é o fortalecimento de identidades e de direitos um dos eixos fundamentais das formações de professores e professoras para a educação infantil, e também um dos princípios orientadores do parecer CNE/CP/03/2004, que estabelece Diretrizes Curriculares Nacionais para a Educação das Relações Étnico-Raciais e para o Ensino de História e Cultura Africana e Afro-Brasileira.

É fundamental destacar que compreendemos identidade

[...] não como qualidade de ser perfeitamente igual, nem tampouco completamente diferente. Identidade, como consciência que uma pessoa tem de si própria, ao ter da sua comunidade, da sua classe, do seu grupo social; consciência que se elabora na experiência do dia a dia com aqueles com quem se convive. A identidade, pois, se explicita nas relações que se dão na família, na comunidade, na escola, no mundo do trabalho. (SILVA, 1987, p. 73)

Com base nesta perspectiva, Souza (2016), em sua tese de doutorado, intitulada Experiências de Infâncias com Produções de Culturas no llê Axé Omo Oxé lbá Latam, destaca que existe uma relação intrínseca e de complementariedade basilar entre o parecer acima mencionado e o parecer $\mathrm{CNE} / \mathrm{CB} / 09 / 2009$, que estabelece Diretrizes Curriculares Nacionais para a Educação Infantil. A correlação entre os princípios de "consciência política e histórica da diversidade e os princípios éticos", "fortalecimento de identidades e de direitos e os princípios políticos" e "ações educativas de combate ao racismo e a discriminação somada aos princípios estéticos" viabilizam a construção de uma educação equânime.

Ainda no referido trabalho, com base em seus dados de pesquisa, Souza (2016) afirma que há um tripé que traz indicativos para a consolidação de uma educação descolonizadora pautada em valores da cosmologia de mundo afro-brasileiro e africano para a educação infantil, e a construção desses indicativos considerou que nas 
[...] epistemologias das crianças implicam as interrogações, os movimentos, o atrevimento em olhar, perguntar e transformar a realidade. Não é a criança quem tem que entrar na lógica do adulto, mas, na lógica exúlica ${ }^{7}$, são os adultos que devem entrar na lógica da criança, pelo óbvio a criança não fora adulto, mas nós os adultos já fomos crianças, então qual a lógica que deve permear as relações verdadeiras? Do contrário, as relações permanecem forjadas, perniciosas e adultocentradas à medida em que forçamos a criança ser o que não é; paralelo a isso, o adulto finge que nunca foi (criança). (SOUZA, 2016, p. 163-164)

Cabe fazer um adendo e destacar que, na compreensão de mundo yorubá, o conceito de criança não se constrói pela oposição semântica com o conceito de adulto, mas se revela como construção da possibilidade de trânsito (portanto, categoria não estática), cujo movimento, transitividade e narratividade, segundo a Semiótica (LOTMAN, 1996; BAKHTIN, 1999), se inserem na ordem e na natureza do axé, força vital e de permanente movimentação. A infância, nesta propositura, sob a prescrição da lógica de Exu, reporta não a si mesma, mas evoca, polifonicamente, diferentes enunciados de estado (gestação, nascimento, infância, adolescência, juventude, adultez, velhice e ancestralização), estados a que se pode ir e vir, numa perspectiva capaz de sabotar a cognição, a interpretação e a representação simbólica eurocêntrica da percepção do tempo. Destarte, o entendimento do que seja "criança” não se constrói cognitivamente por intermédio da relação de oposição, mas passeia por enunciados de estados, ora simultâneos, ora em progressão, não excludentes e "experienciáveis" em qualquer fase da vida.

É na indivisão que se encontra a cosmologia de mundo africana, que não permite um raciocínio binário calcado em divisões superficiais, mas, acima de tudo, não se pauta pela obviedade, pois se estrutura nas singularidades e peculiaridades próprias da

\footnotetext{
7 Só é possível entender a referida lógica exúlica se considerarmos que o indivisível não é uno, mas é múltiplo. O continente africano compreende diversas tradições e não podemos tratá-las como uma única tradição. Hampatê Bâ (2003, p. 1) ressalta, entretanto, que há grandes constantes como "[...] a presença do sagrado em todas as coisas, a relação entre o mundo dos vivos e o mundo dos mortos, o sentido comunitário, o respeito religioso pela mãe". Por isso, é na indivisão múltipla que se encontra a cosmologia de mundo africana, e esta nos apresenta a lógica exúlica, pois não se separa o sagrado do cotidiano, na medida em que mantêm-se vivos e mortos unidos na comunidade. Essa lógica não permite um raciocínio binário calcado em divisões superficiais, mas, acima de tudo, não se pauta pela obviedade, pois estrutura-se nas singularidades e peculiaridades próprias da ancestralidade inerente a cada pessoa, e é a ancestralidade quem faz o ser humano alguém uno e múltiplo na lógica exúlica.
} 
ancestralidade inerente a cada pessoa, e é a ancestralidade que faz do ser humano alguém uno e múltiplo. Compreende-se ancestralidade, conforme Oliveira (2007, p. 30):

Ancestralidade pretensamente advinda da tradição africana, que ressignifica as práticas do povo-de-santo e as aproxima de um manancial de legitimidade - a África mítica - que serve como arma ideológica na disputa do mercado religioso bem como na construção de um projeto político, que passa pela identidade do negro brasileiro. Se de um lado a África-símbolo não é a realidade do continente africano contemporâneo, como dizem os "acadêmicos", de outro é também verdade que este símbolo é utilizado com eficiência na construção da identidade do negro no Brasil.

Com base nesses elementos, como aponta a experiência de pesquisa de Souza (2016), podemos destacar alguns indicativos para a construção de um processo de descolonização da infância, a partir da lógica yorubá, a qual destaca a necessidade de apresentar outras perspectivas de tempo, espaço e corpos, subdividindo-se em: Conceitos orientadores para a construção de uma educação equânime; Lógica Exúlica e Posturas dinamizadoras de equidade. ${ }^{8}$ Dessa forma, os conceitos orientadores se dividem em: ancestralidade (é um valor fundamental para a consolidação identitária dos diferentes grupos humanos); corporalidade (buscar emergir em seu próprio corpo diferentes infâncias) e oralidade (a principal via de transmissão dos valores de ancestralidade) (SOUZA, 2016).

Os conceitos orientadores para a construção de uma educação equânime implicam posturas dinamizadoras que podem estar orientadas pela lógica exúlica, sendo elas:

a) Acolhimento: receber as crianças em sua ancestralidade dispostas a compreender suas epistemologias; isso exige, na lógica exúlica, romper com a noção de tempo e espaço, pois o mais velho não é necessariamente o mais experiente?

\footnotetext{
${ }^{8}$ A metodologia de pesquisa de Souza (2016) aportou-se em inspirações na fenomenologia da percepção e semiótica da cultura reconhecendo as crianças como pesquisadoras, e não apenas sujeitos de pesquisa.

9 O respeito à ancestralidade, bem como o acolhimento e a não hierarquização etária pautada no adultocentrismo são princípios que inspiram a construção de pedagogias descolonizadoras; deste modo, poderíamos afirmar que a lógica exúlica está presente na construção dos estudos e pensamentos póscoloniais.
} 
b) Cumplicidade: dispor o corpo para se colocar nos diferentes lugares com os outros, construindo com estes/as relações circulares pautadas, que implica a lógica exúlica em considerar que a infância é um estado e, por isso, pode um adulto ser infantil enquanto aprende-ensina-aprende, e pode ainda viver múltiplas infâncias em si mesmo na sua corporalidade.

c) Transformação: destinar com as crianças outras finalidades a ações e objetos não estabelecidos socialmente, considerando por meio da lógica exúlica o poder materializador das palavras, sendo esta sempre concreta, independente da escrita, por isso há que se comprometer com o que se expressa, seja ouvindo ou proferindo, por meio da oralidade.

As considerações da referida pesquisa se organizam na coleta de dados com as crianças; a lógica exúlica se circunscreve em uma perspectiva de descolonização dos saberes, considerando que as culturas infantis trazem um potencial intempestivo - cuja constituição se faz pelo pensamento sem imagem, constituindo-se como o espaço da diferença - intrínseco à sua natureza descolonizadora, promovendo possibilidades de repensarmos a formação docente, os conceitos de ancestralidade. A corporalidade e a oralidade são consolidadas na medida em que as crianças produzem culturas e têm suas produções legitimadas pelos atores e atrizes sociais que determinam pedagogias estabelecidas nas creches e pré-escolas.

Inerente a esse processo é colocada outra questão:

Que somos nós, para as crianças que brincam ao nosso redor, senão sombras? Elas nos cercam, choram contra nós, respondem às nossas perguntas, num tom de condescendência, quando fingimos interessarnos por suas atividades; mas sente-se, perfeitamente, que para elas, somos como os móveis da casa, parte do cosmo exterior, não pertencente a seu mundo, que tem seus prazeres e seus sofrimentos. (BASTIDE, 2004, p. 195)

Para diminuir esse distanciamento, é fundamental rompermos as fronteiras que delimitavam o universo adulto e o das crianças; as culturas infantis nessa ação podem ser como estrelas que "nos posicionam", indicando possibilidades para a desconstrução da 
colonização historicamente imposta à formação docente, por isso, são as relações que estabelecemos com as crianças que podem permitir uma navegação segura em busca de uma educação que se quer equânime ${ }^{10}$.

Em uma navegação com as crianças das creches e pré-escolas, podemos brincar de esconde-esconde, quando podemos, junto das meninas e dos meninos, encontrar a nossa ancestralidade, de forma a reconhecer os bônus e os ônus que esta traz a nossa formação docente. Podemos modificar e movimentar nossos corpos, de forma a experimentar as possibilidades que as diferentes infâncias nos dão de movimentar a nossa prática docente e, por fim, construir novos acordos coletivos que possibilitem a construção de pedagogias descolonizadas.

As possibilidades de construções de pedagogias descolonizadoras vêm sendo estudadas desde o doutorado de Faria (2002), que analisou a construção dos parques infantis em São Paulo, idealizados por Mario de Andrade. Como aponta a autora, a partir dessa experiência podemos pensar elementos fundantes para a descolonização da educação infantil, dentre eles estão o trabalho coletivo, a pesquisa e vontade política, bem como o reconhecimento do outro, seja este outro a criança, o operário ou a operária, o nordestino e a nordestina e o reconhecimento dos nossos "ideias" que "não podem ser iguais aos da França porque as nossas necessidades são inteiramente outras, nosso povo outro, nossa terra outra etc." (cf ANDRADE, apud FARIA, 2002, p. 171).

As construções de pedagogia descolonizada não obedecem a uma única forma, mas têm em sua gênese o projeto de transformação social, em que um dos princípios é a superação das desigualdades e a construção da equidade entre as relações de gênero, étnico-racial e sexual, bem como entre as idades.

O processo de construção de pedagogias descolonizadoras impõe uma força criadora que tenciona a formação docente arquitetada sobre o legado colonial racista e adultocêntrico, permitindo os novos olhares e escutas que se encontram com as produções das crianças, bem como favorece a inspiração de pensamentos não binários. A

\footnotetext{
${ }^{10}$ É necessário destacar que a equidade pressupõe o reconhecimento das diferenças, o que exige criar condições para que estas não sejam transformadas em desigualdades, e, para tanto, é preciso buscar outras referências e lógicas para navegar com segurança e não nos perdermos nos ranços históricos da colonização.
} 
formação docente torna-se assim um enredo de invitações à desconstrução de pensamentos enrijecidos pela estrutura colonial, imposta pela modernidade.

Que acham se delirarmos um pouquinho? Que acham se fixarmos nossos olhos mais além da infâmia? Para imaginarmos outro mundo possível. 0 ar estará limpo de todo veneno que não venha dos medos humanos e das humanas paixões. [...] Assim como canta o pássaro sem saber que canta, e como brinca a criança sem saber que brinca... (GALEANO, $O$ direito ao delírio, apud STEVAUX, 2011, p. 58-9)

\section{Referências}

BAKHTIN, Mikhail. Marxismo e filosofia da linguagem. São Paulo: HUCITEC, 1999.

BARROS, Manuel. Memórias inventadas: as infâncias de Manoel de Barros. São Paulo: Planeta do Brasil, 2010.

BASTIDE, Roger. Prefácio do capítulo as trocinhas do Bom Retiro. In: FERNANDES, Florestan. Folclore e mudança social na cidade de São Paulo. São Paulo: Martins Fontes, 2004, p. 195-199.

BENJAMIN, Walter. Reflexões sobre a criança, o brinquedo e a educação. São Paulo: Editora 34, 2002.

BRAH, Avat. Diferença, diversidade, diferenciação. Cadernos Pagu. Campinas, v. 26, p. 329-376, 2006.

BRANDÃO, Carlos Rodrigues. A educação como cultura. São Paulo: Brasiliense, 2010.

BUFALO, Joseane Maria Parice. Creche: lugar de criança, lugar de infância; um estudo sobre as práticas educativas em um CEMEI de Campinas/SP. 1997. Dissertação (Mestrado em Educação) - Universidade Estadual de Campinas, Faculdade de Educação, Campinas, 1997.

CORSARO, Willian Arnold. Le culture dei bambini. Bologna: Il Molino, 2003.

CORSARO, Willian Arnold. Sociologia da infância. Porto Alegre: Artmed, 2011. 
FALEIROS, Vicente de Paula. Infância e processo político no Brasil. In. RIZZINI, Irene; PILOTTI, Francisco (Orgs.). A arte de governar crianças: a história das políticas sociais, da legislação e da assistência à infância no Brasil. 3. ed. São Paulo: Cortez, 2011.

FARIA, Ana Lúcia Goulart de. Educação pré-escolar e cultura: para uma pedagogia da educação infantil. Campinas - SP: Cortez/Coedição Editora Unicamp, 2002.

FERNANDES, Florestan. A integração do negro na sociedade de classes. São Paulo: Ed. Nacional, 1965.

FERNANDES, Florestan. As trocinhas do Bom Retiro. In: Folclore e mudança social na cidade de São Paulo. São Paulo: Martins Fontes, 2004, p. 203-315.

FOUCAULT, Michel. História da sexualidade: o uso dos prazeres. Rio de Janeiro: Graal, 2010.

GUATTARI, Felix. As creches e a iniciação. In: GUATTARI, Felix, Revolução molecular. São Paulo: Editora Brasiliense, 1987. p. 50-55.

HAMPATE BÂ, Amadou. Amkollel, o menino fula. Tradução Xina Smith de Vasconcellos. São Paulo: Casa das Áfricas e Pallas Athena, 2003.

KI-ZERBO, Joseph. História geral da África - I. Brasília -DF: UNESCO, 2010.

LOTMAN, Iuri. La se miosfera I: semiótica de la cultura y del texto. Valência: Frónesis Cátedra, 1996.

MACEDO, Elina Elias. Crianças pequenininhas e a luta de classes. 2016. Tese (Doutorado em Educação) - Universidade Estadual de Campinas, Faculdade de Educação, Campinas, 2016.

MIGUEL, Antônio. Exercícios descolonizadores a título de prefácio: isto não é um prefácio e nem um título. In: FARIA, Ana Lúcia Goulart et al. Infância e Pós-colonialismo: pesquisas em busca de pedagogias descolonizadoras. Campinas: Leitura Crítica: Associação de Leitura do Brasil, 2015, p. 25- 55.

MANFERRARI, Marina. Histórias são naus que cruzam fronteiras. Pro-Posições, Campinas, v. 22, n. 2 (65), p. 51-62, maio/ago., 2011.

MARX, Karl; ENGELS, Friedrich. A história dos homens. In: MARX, Karl; ENGELS, Friedrich. A ideologia alemã. São Paulo: Martins Fontes, 2000, p. 182-214.

MAUSS, Marcel. Três observações sobre a sociologia da infância. Pro-Posições, Campinas, v. 21, n. 3 (63), p. 237-244, 2010.

MIRANDA, Carlos Educado Albuquerque. Abertura comenius e o silencio da Imaginação. In: FARIA, Ana Lúcia Goulart de; MELLO, Suely Amaral. Territórios da infância: linguagens, tempos e relações para uma pedagogia para as crianças pequenas. Araraquara: Juqueira\&Marin, 2009. p. 17-31. 
OLIVEIRA, Eduardo David. A ancestralidade na encruzilhada. Curitiba: Gráfica Popular, 2007.

PRADO, Patrícia Dias. Educação e cultura infantil em creche: um estudo sobre as brincadeiras de crianças pequenininhas em um CEMEI de Campinas/SP. 1998. Dissertação (Mestrado em Educação) - Universidade Estadual de Campinas, Faculdade de Educação, Campinas, 1998.

PINTO, Regina Pahim. O movimento Negro em São Paulo: luta e identidade. Ponta Grossa: UEPG, 2013.

PIOZZI, Patrizia. Marx, o operário, e as leis da beleza. Mouro-Revista Marxista. São Paulo: Núcleo de Estudos d'O capital, ano 6, n. 9, p. 132-143, jan., 2015.

QVORTRUP, Jens. Visibilidades das crianças e da infância. Linhas Críticas, Brasília - DF, v. 20, n. 41, p. 23-42, jan./abr. 2014.

QVORTRUP, Jens. A dialética entre a proteção e a participação. Currículo sem Fronteiras, Belo Horizonte, v. 15, n. 1, p. 11-30, jan./abr. 2015.

ROCHA, Eloisa Acires Candal. Infância e pedagogia: dimensões de uma intricada relação. Perspectiva. Florianópolis, v. 15, n. 28, p. 21-33, 1997.

ROSEMBERG, Fúlvia. Educação: para quem? Ciência e Cultura. São Paulo, n. 28 (12), p. 1467-1471, 1976.

ROSEMBERG, Fúlvia. Do embate para o debate: educação e assistência no campo da educação infantil. In: MACHADO, Maria Lucia de (org.). Encontros e desencontros em educação infantil. São Paulo: Cortez, 2002, p. 63-78.

SANTIAGO, Flávio. Gritos sem palavras: resistências das crianças pequenininhas negras frente ao racismo. Educação em Revista, Belo Horizonte, v. 31, p. 129-153, 2015.

SANTIAGO, Flávio. As crianças negras e o racismo. Pátio, Porto Alegre, v. 47, 2016, p. 4143.

SANTIAGO, Flávio; FARIA, Ana Lúcia Goulart de. Para além do adultocentrismo: uma outra formação docente descolonizadora é preciso. Revista Educação e Fronteiras [on-line], Dourados - MS, v. 3, p. 90-104, 2015. Disponível em:

<http://ojs.ufgd.edu.br/index.php/educacao/article/view/5184/pdf_301>.

SANTOS, Boaventura de Sousa. Para uma sociologia das ausências e uma sociologia das emergências. Revista Crítica de Ciências Sociais, Coimbra/Portugal, n.63, p.237-280, 2002.

SANTOS, Boaventura de Sousa. Para além do pensamento abissal: das linhas globais a uma ecologia dos saberes. In: SANTOS, Boaventura de Sousa; MENESES, Maria Paula (Orgs). Epistemologias do Sul. São Paulo: Cortez, 2010. 
SANTOS, Solange Estanislau. ; SANTIAGO, Flavio; FARIA, Ana Lúcia Goulart de. Manifesto (des)educado: profanações pós-coloniais. Revista Textura (ULBRA), Canoas- RS, v. 18, 2016, p. 191-205.

SANTOS, Solange Estanislau dos Santos. As crianças (in) visíveis nos discursos políticos da educação infantil: entre imagens e palavras. 2014. 142f. Tese (Doutorado em Educação) - Universidade Estadual de Campinas, Faculdade de Educação, Campinas, 2014.

SCOTT, Joan Wallach. A invisibilidade da experiência. Proj História, São Paulo, v. 16, 1998, p. 297-323.

SILVA, Petronilha Beatriz Gonçalves e Silva. Educação e identidade dos negros trabalhadores rurais do Limoeiro. 1987. Tese de (Doutorado em...) - Universidade Federal do Rio Grande do Sul, Faculdade de Educação, Porto Alegre, 1987.

SOUZA, Ellen de Lima. Percepções de infância negra, por professoras de educação infantil. 2012. Dissertação (Mestrado em Educação) - Universidade Federal de São Carlos, São Carlos, 2012.

SOUZA, Ellen de Lima. Experiências de infâncias com produções de culturas no llê Axé Omo Oxé Ibá Latam. 2016. Tese (Doutorado em Educação) - Universidade Federal de São Carlos, São Carlos, 2016.

SPIVAK, Gayatri Chakravorty. Pode o subalterno falar? Belo Horizonte: Editora UFMG, 2010.

STEVAUX, Fernando Peixoto. O socialismo utópico de Charles Fourier e sua utopia de infância e educação das crianças. 2011. Trabalho de Conclusão de Curso (Curso Pedagogia) - Universidade Estadual de Campinas, Campinas, 2011.

THOMPSON, Edward Palmer. Costumes em comum. São Paulo: Companhia das Letras, 1998.

VELHO, Gilberto. Observando o familiar. In: NUNES, Edson Oliveira. A aventura Sociológica. Rio de Janeiro: Jorge Zahar, 1978, p. 36-46. 